\title{
PERANCANG SISTEM PAKAR DIAGNOSIS KERUSAKAN PERANGKAT KERAS MENGGUNAKAN POHON KEPUTUSAN
}

\author{
Nursafitri Meylani Pane', Mochammad Sisin Saiful Umam², Fitriani Noor Fauziah ${ }^{3}$ \\ 1,2,3 Manajemen Informatika, Politeknik Pos Indonesia \\ nursafitrim05@gmail.com, email: moch.sisin@gmail.com, email: fitrianif1602@gmail.com
}

\begin{abstract}
The development of computer technology is also followed by the increasing number of computer users in the world. Along with the increasing number of computer users, the problem of computer damage has become quite a complicated problem. This is understandable considering the number of computer users who lack knowledge about computers, especially in dealing with computer damage. In addition, the limited memory and knowledge of a technician about computer damage can cause errors or inaccuracies in diagnosing the damage. In designing this system the approach method used is structured oriented with the system development method used is a prototype model. The supporting software used to design a food menu ordering information system is Power Designer, Bizagi Modeler, Balsamiq, and Microsoft Visio. The final result of this activity is in the form of an expert system design report to diagnose web-based hardware damage. With the expert system created, it is expected to be able to overcome errors in determining damage caused by limited memory of technicians.
\end{abstract}

Keywords: Expert System, Decision Tree, Prototyping

\section{PENDAHULUAN}

Komputer merupakan suatu perangkat elektronika yang dapat menerima dan mengolah data menjadi informasi, menjalankan program yang tersimpan dalam memori, serta dapat bekerja secara otomatis dengan aturan tertentu. Secara fungsional, komputer sangat besar manfaatnya dan sangat dibutuhkan oleh manusia untuk meringankan pekerjaan. Hal ini karena komputer memiliki beberapa keunggulan dibandingkan dengan kemampuan manusia. Diantaranya, proses pengolahannya lebih cepat, tingkat akurasi informasinya lebih tinggi, lebih efisien dan bersifat interaktif.

Perkembangan teknologi komputer diikuti pula dengan meningkatnya jumlah pengguna komputer di dunia. Seiring dengan meningkatnya jumlah pengguna komputer, permasalahan kerusakan komputer menjadi masalah yang cukup rumit. Hal ini dapat dimaklumi mengingat banyaknya pengguna komputer yang kurang memiliki pengetahuan tentang komputer, khususnya dalam menangani kerusakan komputer. Permasalahan ini secara umum dialami baik oleh individu maupun institusi, banyak sekali dana yang dikeluarkan untuk memperbaiki kerusakan komputer, padahal kerusakan komputer yang terjadi belum tentu rumit dan dapat diperbaiki secara mandiri. Selain itu, adanya keterbatasan daya ingat dan pengetahuan seorang teknisi mengenai kerusakan komputer menimbulkan kesalahan atau ketidakakuratan dalam mendiagnosis kerusakan.

Oleh karena itu, dirancanglah Sistem Pakar untuk Diagnosis Kerusakan Hardware Komputer Berbasis Web Menggunakan Pohon Keputusan. Dengan adanya sistem pakar yang dapat mengidentifikasi kerusakan hardware pada komputer, diharapkan dapat membantu para pengguna komputer dalam mengatasi setiap kerusakan hardware komputer .

\section{KAJIAN LITERATUR}

Sistem Pakar

Menurut Kusrini dalam Muhammad Rino Prayogi Siahaan (2015:80) Sistem pakar adalah aplikasi berbasis komputer yang digunakan untuk menyelesaikan masalah sebagaimana yang dipikirkan oleh pakar

Sistem pakar adalah sistem komputer yang ditujukan untuk meniru semua aspek (emulates) kemampuan pengambilan keputusan (decision 
making) seorang pakar. Sistem pakar memanfaatkan secara maksimal pengetahuan khusus selayaknya seorang pakar untuk memecahkan masalahBagian ini berisi kajian literatur yang dijadikan sebagai penunjang konsep penelitian.

Sistem pakar memiliki beberapa komponen utama, yaitu antarmuka pengguna (user interface), basis data sistem pakar (expert system database), fasilitas akuisi pengetahuan (knowledge acquisition facility) dan mekanisme inferensi (inferensi mechanism)

\section{Pohon Keputusan}

Sebuah pohon keputusan adalah sebuah struktur yang dapat digunakan untuk membagi kumpulan data yang besar menjadi himpunan-himpunan record yang lebih kecil dengan menerapkan serangkaian aturan-aturan keputusan. Dengan masing-masing rangkaian pembagian, anggota himpunan hasil menjadi mirip satu dengan yang lain (Berry dan Linnof, 2004).

Pohon keputusan merupakan himpunan aturan jika...maka. Setiap lintasan dalam pohon dihubungkan dengan sebuah aturan, di mana premis terdiri atas sekumpulan node-node yang ditemui, dan kesimpulan dari aturam terdiri atas kelas yang terhubung dengan daun dari lintasan

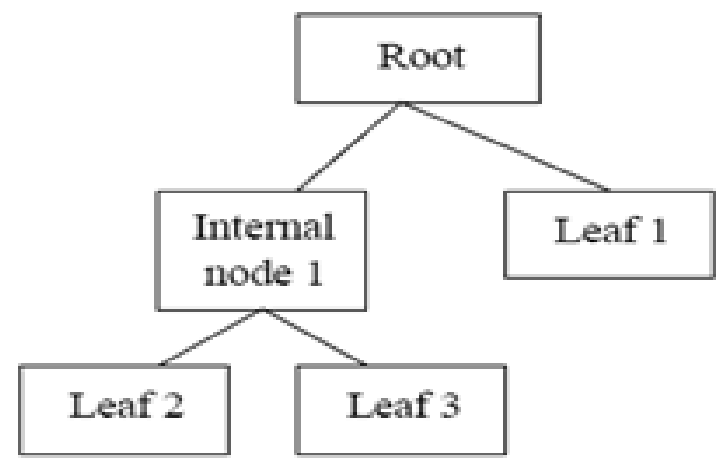

Gambar 1. Konsep dasar pohon keputusan

Bagian awal dari pohon keputusan ini adalah titik akar (root), sedangkan setiap cabang dari pohon keputusan merupakan pembagian berdasarkan hasil uji, dan titik akhir (leaf) merupakan pembagian kelas yang dihasilkan

\section{Analisis Umum}

Analisis umum bisa dilakukan dengan mengambarkan rantai nilai bengkel komputer. Rantai Nilai (Porter) adalah model yang digunakan untuk membantu menganalisis aktifitas - aktifitas spesifik yang dapat menciptakan nilai dan keuntungan kompetitif bagi organisasi.

\section{Rantai Nilai (Porter)}

Analisis umum bisa dilakukan dengan mengambarkan rantai nilai bengkel komputer. Rantai Nilai (Porter) adalah model yang digunakan untuk membantu menganalisis aktifitas - aktifitas spesifik yang dapat menciptakan nilai dan keuntungan kompetitif bagi organisasi.

Support

Activities

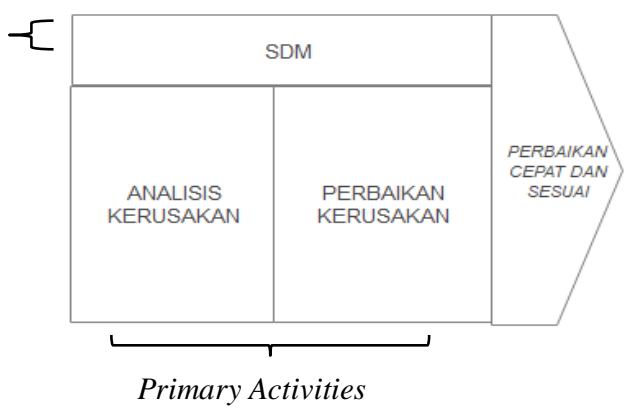

Gambar 2. Rantai Nilai Porter

\section{METODE PERANCANGAN}

Dalam perancangan ini, penulis menggunakan systems development life cycle prototyping. Prototyping perangkat lunak atau siklus hidup menggunakan protoyping adalah salah satu metode siklus hidup sistem yang didasarkan pada konsep model bekerja.Tujuannya adalah mengembangkan model menjadi sistem final. Artinya sistem akan dikembangkan lebih cepat daripada metode tradisional dan biayanya menjadi lebih rendah. Ada banyak cara untuk memprotoyping, begitu pula dengan penggunaannya. Ciri khas dari metodologi adalah pengembang sistem, klien, dan pengguna dapat melihat dan melakukan eksperimen dengan bagian dari sistem komputer dari sejak awal proses pengembangan. Protoyping membantu dalam menemukan kebutuhan di tahap awal pengembangan, terutama jika klien tidak yakin dimana masalah berasal. Selain itu protoyping juga berguna sebagai alat untuk mendesain dan memperbaiki user interface bagaimana sistem akan terlihat oleh orang-orang yang menggunakannya. 


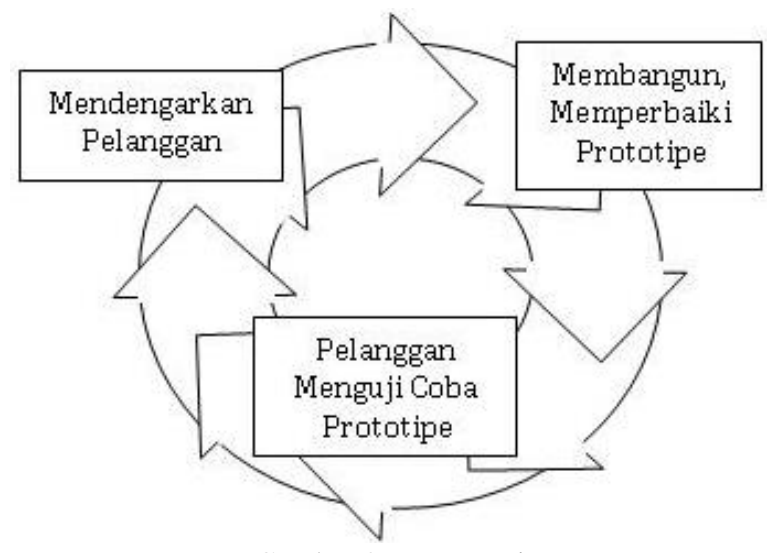

Gambar 3. pPrototyping

Prototyping ini dipilih karena semua fase dapat dilakukan berulang dalam siklus sampai sistem selesai. Selain itu bisa mengulang tahapan-tahapan dengan cepat karena ada perubahan kebutuhan pengguna.

\section{HASIL DAN PEMBAHASAN}

\section{Perancangan Sistem}

Perancangan sistem yang digambarkan dengan CD (Context Diagram) dan DFD (Data Flow Diagram) untuk menggambarkan sistem informasi yang akan dibangun.

\section{Diagram Konteks}

Berikut adalah Context Diagram dari sistem yang akan dibangun

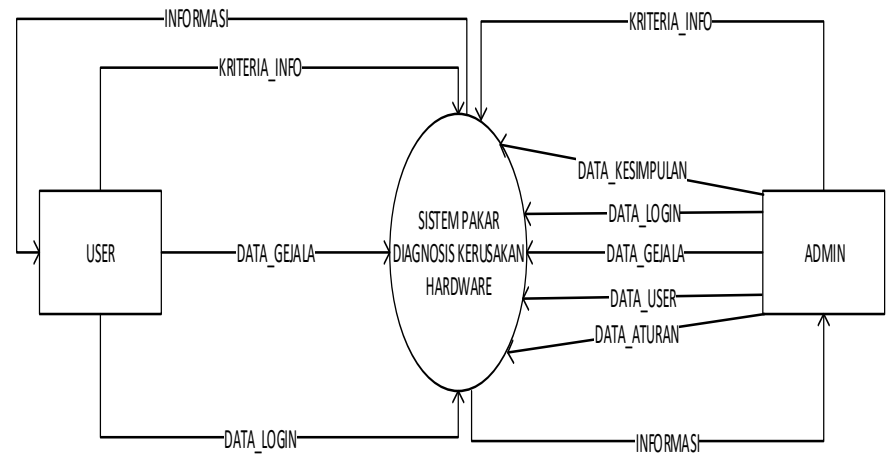

Gambar 4. Diagram Konteks

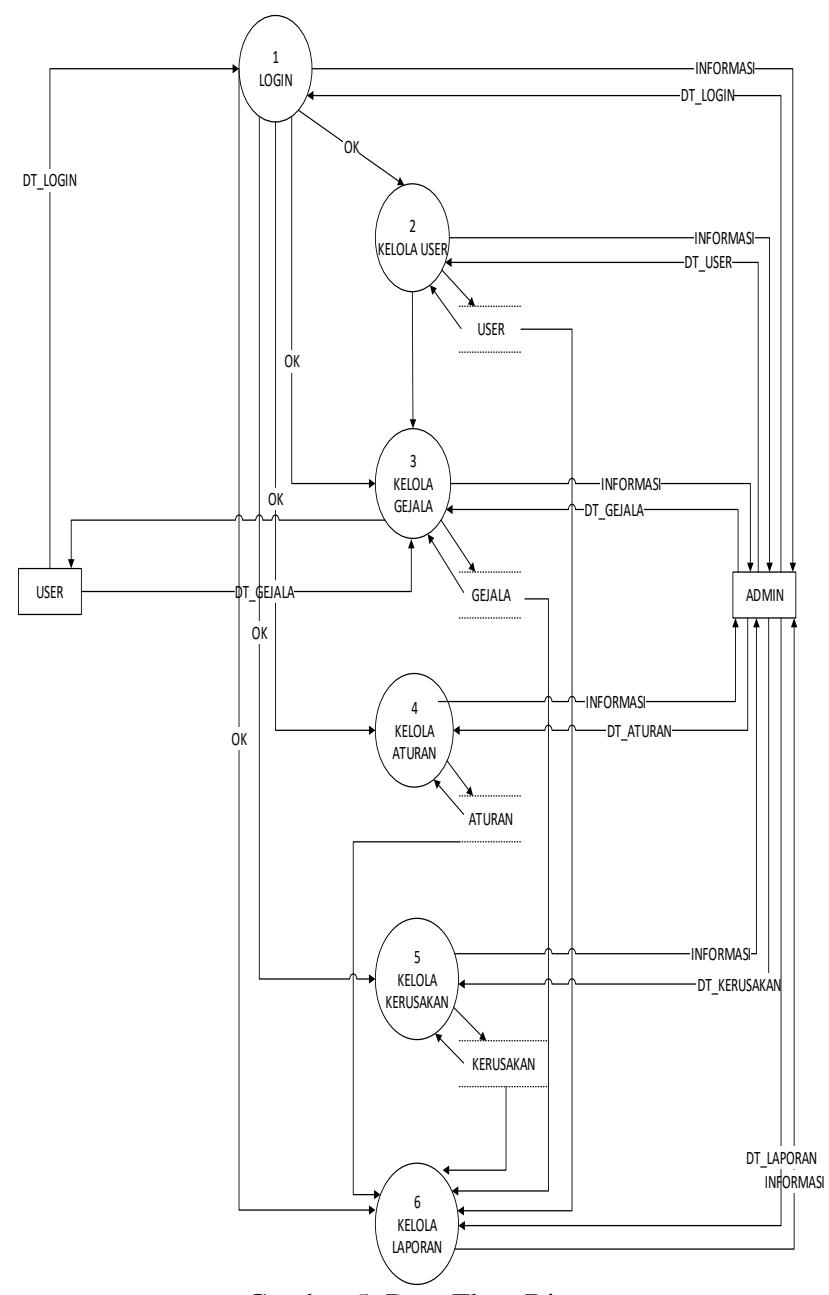

Gambar 5. Data Flow Diagram

\section{Perancangan Database}

Perancangan Database yang digambarkan dengan ERDiagram untuk menggambarkan sistem yang akan dibangun.. Berikut adalah ER-Diagram sistem yang akan dibangun :

\section{Data Flow Diagram Level 1}

Berikut adalah DFD level 1 dari sistem yang akan dibangun : 


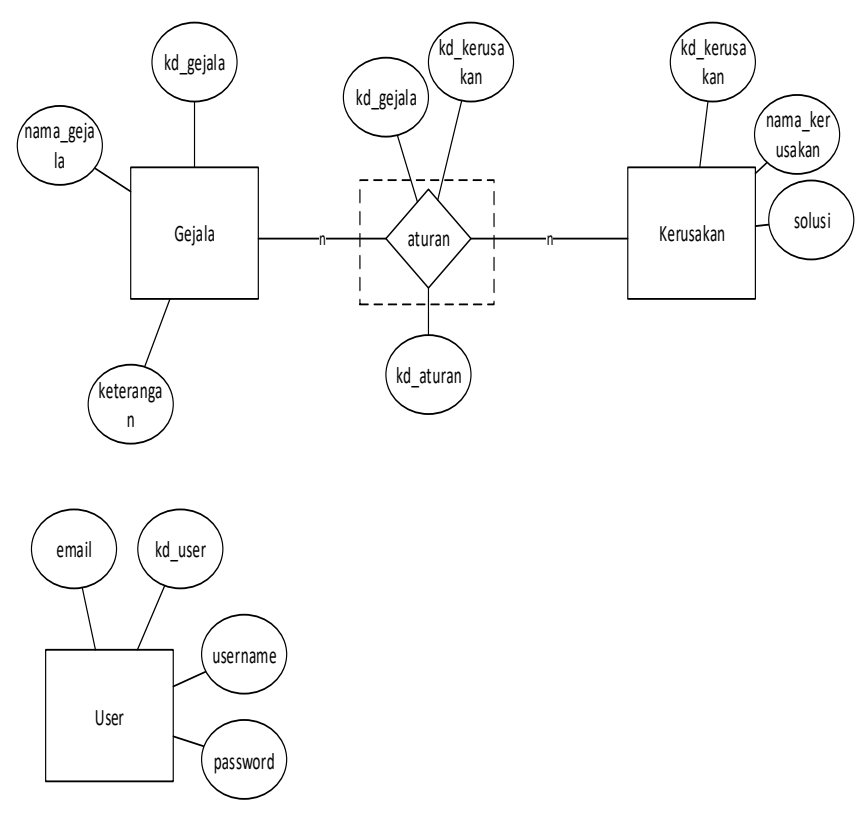

Gambar 6. ERD

\section{Perancangan Antar Muka}

\section{Struktur Menu}

Struktur menu menggambarkan fitur-fitur yang akan dirancang untuk membangun aplikasi berbasis web.

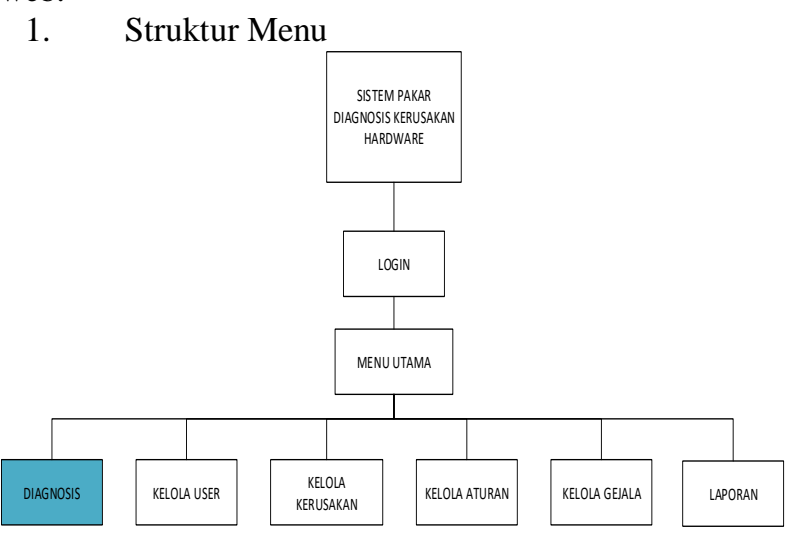

Gambar 7. Struktur Menu

Keterangan:

$$
\begin{aligned}
& \square \text { = Dapat di akses seluruh user puskesmas } \\
& \square \text { = Hanya dapat di akses oleh administrator } \\
& \text { atau pakar }
\end{aligned}
$$

\section{Antar Muka}

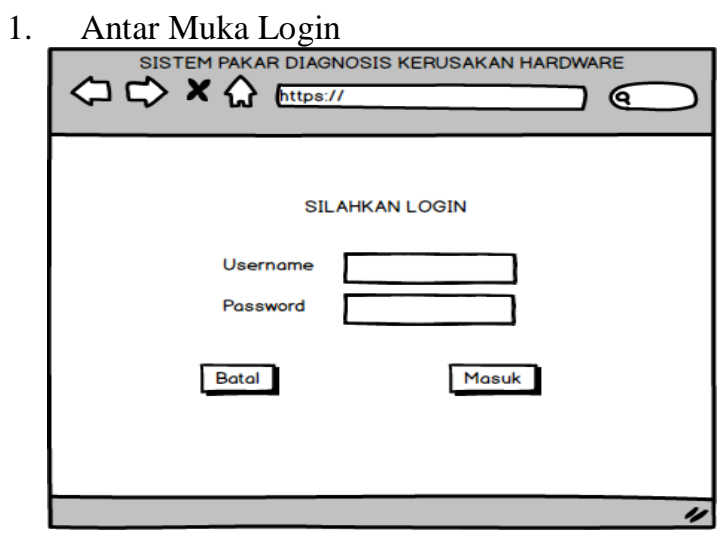

Gambar 8. Antar Muka Login

2. Antar Muka Menu Diagnosa

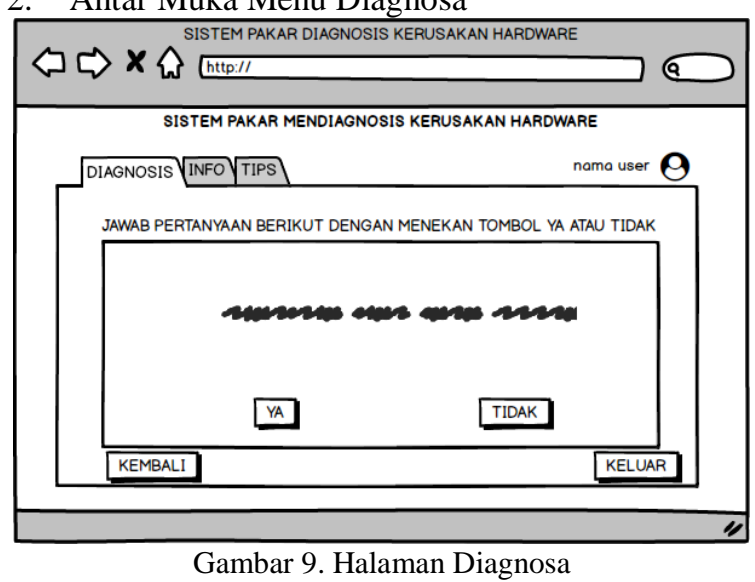

3. Antar muka Kelola Gejala

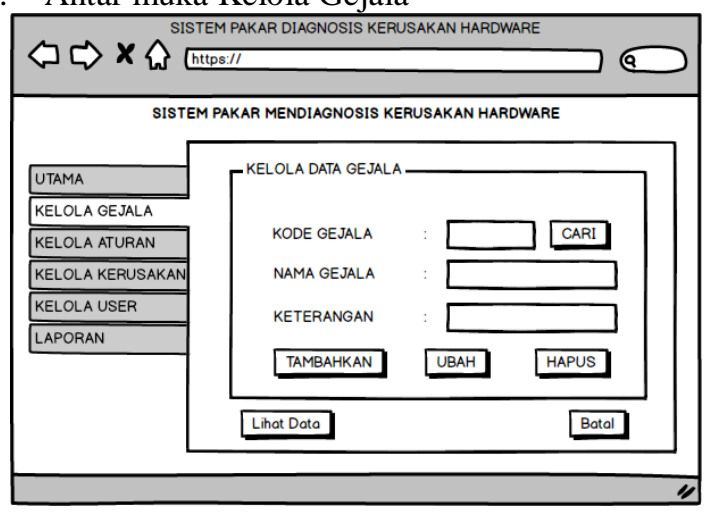

Gambar 10. Halaman Kelola Gejala 
4. Antar Muka Kelola Aturan

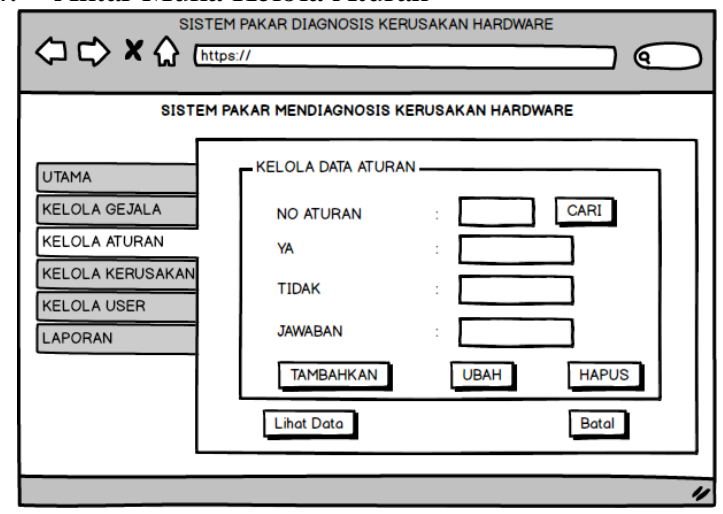

Gambar 11 Halaman Kelola Aturan

5. Antar Muka Kelola Kerusakan

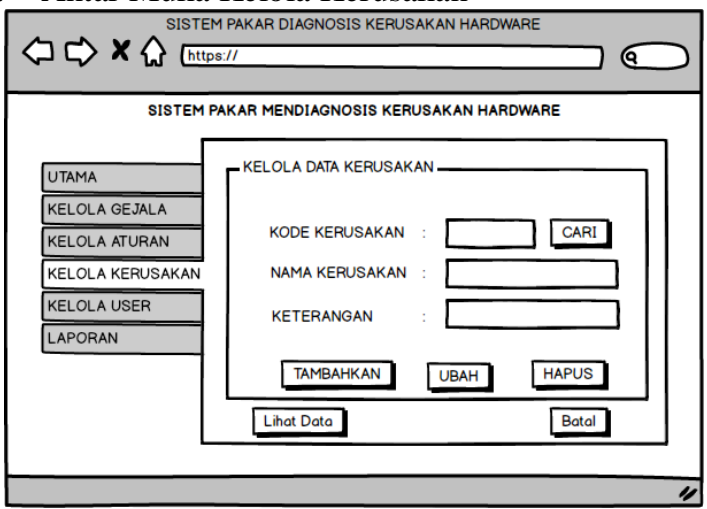

Gambar 12. Halaman Kelola Kerusakan

6. Antar Muka Laporan

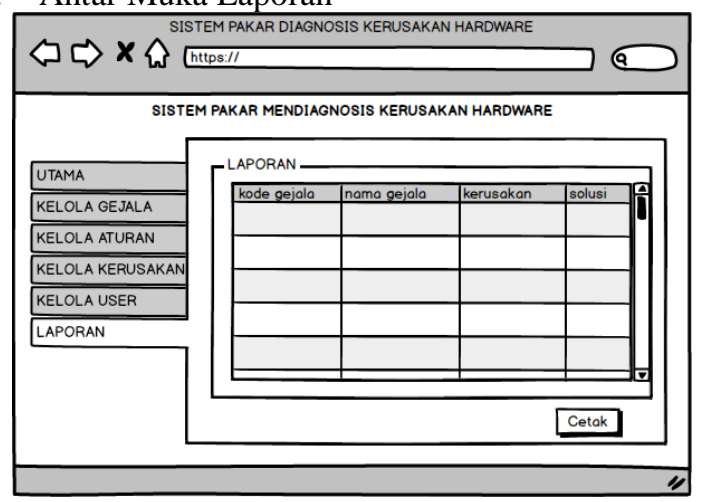

Gambar 13 Halaman Laporan

\section{KESIMPULAN}

Dari hasil perancangan sistem pakar ini, didapatkan suatu rancangan sistem yang dapat mendeteksi suatu kerusakan perangkat keras pada komputer berbasis web. Sehingga,dapat menanggulangi kesalahan penentuan kerusakan yang diakibatkan keterbatasan daya ingat teknisi. Selain dapat menginputkan data gejala, sistem ini juga memiliki fitur kelola aturan, kelola kerusaan dan view laporan.

\section{DAFTAR PUSTAKA}

[1]. Admin. (2016, Januari 7). Balsamiq Mockup.

[2]. Ali, U. (2017, April 3). Pengertian Diagram Konteks dan Data Flow Diagram (DFD). Pengertian Data Flow Diagram (DFD).

[3]. Annisa, M. A. (2015, Januari 13). Cara Membuat Database Menggunakan Power Designer 16.5.

[4]. DosenIT. (2015). Pengertian Sistem Informasi Menurut Para Ahli. Retrieved from https://dosenit.com/kuliahit/sistem-informasi/pengertian-sistem-informasimenurut-para-ahli

[5]. Fatimah, T., \& Anjasari, V. A. (2006). TUGAS AKHIR. SISTEM PAKAR DIAGNOSIS PENYAKIT INFEKSI PADA ANAK (Penyebab Fever Of Unknown Origin).

[6]. Feronika, N. (2016, Juni 27). PENGENALAN MICROSOFT OFFICE VISIO.

[7]. Hutahean, J. (2014). Konsep Sistem Informasi. Yogyakarta.

[8]. Mubarok, M. I. (2018). SKRIPSI. Pohon Regresi Dengan Pendekatan Generalized Unbrased Interaction (Guide) Untuk Data Multirespon.

[9]. Rosnelly, R. (2012). SISTEM PAKAR : KONSEP dan TEORI. Yogyakarta.

[10].sn, R. (2013, November 20). BIZAGI \& BLUEBERRY. BIZAGI, p. Rabu.

[11].Suyanto, M. (n.d.). PENGANTAR TEKNOLOGI INFORMASI UNTUK BISNIS. Yogyakarta.

[12].Tarup, J. (2016, Agustus). Pengertian Microsoft Word 2010 dan Mengenal Lebih Dekat. Pengertian. 